\title{
A Novel Aromatic Iodination Method, with Sodium Periodate Used as the Only Iodinating Reagent ${ }^{\dagger}$
}

\section{Piotr Luliński, Maciej Sosnowski and Lech Skulski*}

Chair and Laboratory of Organic Chemistry, Faculty of Pharmacy, Medical University, Banacha 1, PL 02-097 Warsaw, Poland

$\dagger$ Preliminary data presented at the Seventh Electronic Conference on Synthetic Organic Chemistry (ECSOC-7, http://www.mdpi.net/ecsoc-7), November 1-30, 2003 (paper A013)

* To whom the correspondence should be addressed; Tel./Fax: +(48) 22 5720643; E-mail: lechskulski@yahoo.com

Received: 10 November 2004 / Accepted: 10 March 2005 / Published: 13 May 2005

\begin{abstract}
Benzene, halobenzenes and some deactivated arenes readily reacted in anhydrous $\mathrm{NaIO}_{4} / \mathrm{AcOH} / \mathrm{Ac}_{2} \mathrm{O} /$ concd. $\mathrm{H}_{2} \mathrm{SO}_{4}$ mixtures to afford, after quenching with excess aqueous $\mathrm{Na}_{2} \mathrm{SO}_{3}$ solution (a reducing agent), purified iodinated products in 27$88 \%$ yields. This novel method of aromatic iodination is simple, fairly effective and environmentally safe.
\end{abstract}

Keywords: Arenes, iodoarenes, aromatic iodination, sodium periodate, periodyl organic intermediates.

\section{Introduction}

Only inorganic iodine(VII) derivatives are known and up to now not a single organoiodine(VII) compound has been synthesized and investigated [1,2]. The few reported attempts to synthesize periodylarenes, $\mathrm{ArIO}_{3}$, ended in failure. Willgerodt [3] oxidized iodylbenzene, $\mathrm{PhIO}_{2}$, with a hot 30\% solution of perchloric acid, expecting to obtain periodylbenzene ("Superjodobenzol" or "Phenyljodtrioxyd"), $\mathrm{PhIO}_{3}$, but he obtained instead some white explosive crystals, probably an aromatic iodonium salt, $\mathrm{Ph}_{2} \mathrm{I}^{+} \mathrm{ClO}_{4}{ }^{-}$. Lewitt and Iglesias [4] attempted to prepare $\mathrm{PhIO}_{3}$ by adding benzene dropwise to a chilled solution of $\mathrm{H}_{5} \mathrm{IO}_{6}$ in concd. $\mathrm{H}_{2} \mathrm{SO}_{4}$, but reported obtaining only a $48 \%$ 
yield of periodobenzene, $\mathrm{C}_{6} \mathrm{I}_{6}$; they observed, however, that the initially colorless $\mathrm{H}_{5} \mathrm{IO}_{6} / \mathrm{concd} \mathrm{H}_{2} \mathrm{SO}_{4}$ solution, after adding the benzene, turned first green, then red, and finally light yellow, as the yellow$\tan \mathrm{C}_{6} \mathrm{I}_{6}$ gradually precipitated out. They remarked that the first formed green intermediate (presumably $\mathrm{PhIO}_{3}$ ) and the next red one should be further studied, and invited any investigators interested in this unusual reaction to pursue this avenue of research. Mattern [5] improved the above protocol for preparing either $\mathrm{C}_{6} \mathrm{I}_{6}(45 \%)$ or $1,2,4,5-\mathrm{C}_{6} \mathrm{H}_{2} \mathrm{I}_{4}(60 \%)$ from benzene, but he made no attempt to study the green and red intermediates observed by Levitt and Iglesias [4]. Similarly, nobody has succeeded in preparing and investigating any single organobromine(VII) compound, while in contrast, the stable and unusually resistant to reduction perchloryl aromatics, $\mathrm{ArClO}_{3}$, have been known since 1958 [6].

\section{Results and Discussion}

As a continuation of our systematic studies on effective aromatic iodination reactions, which are related in detail in our two latest reviews [7,8], we recently decided to use sodium periodate $\mathrm{NaIO}_{4}$, alone, as an iodinating reagent. The reactions were carried out in anhydrous acetic acid/acetic anhydride solvent mixtures containing $\mathrm{NaIO}_{4}$ and a chosen arene (Table 1), and then strongly acidified with varied amounts (see Table 1) of concd. (95\%) sulfuric acid. We expected that the following subsequent reactions would probably proceed in the acidified reaction mixtures, viz.:

$$
\begin{aligned}
& \mathrm{NaIO}_{4}+\mathrm{H}_{2} \mathrm{SO}_{4} \longrightarrow \mathrm{HIO}_{4}+\mathrm{NaHSO}_{4} \\
& \stackrel{\cdot}{\mathrm{H}}-\mathrm{IO}_{3}+\mathrm{H}_{2} \mathrm{SO}_{4} \longrightarrow \mathrm{H}_{2} \stackrel{+}{\mathrm{O}}-\mathrm{IO}_{3}+\mathrm{HSO}_{4}^{-} \\
& \stackrel{+}{\mathrm{H}_{2} \stackrel{\mathrm{O}^{-}}{-}} \longrightarrow \mathrm{IO}_{3} \longrightarrow \mathrm{H}_{2} \mathrm{O}+\left[\mathrm{IO}_{3}\right]^{+} \text {(presumably, a strong electrophile) } \\
& \mathrm{ArH}+\left[\mathrm{IO}_{3}\right]^{+} \longrightarrow\left[\mathrm{ArIO}_{3}\right]+\mathrm{H}^{+}
\end{aligned}
$$

where: $\left[\mathrm{IO}_{3}\right]^{+}$represents hypothetical transient periodyl cations and $\left[\mathrm{ArIO}_{3}\right]$, the non isolable (vide infra), hypothetical periodyl intermediates. We must admit that in spite of our numerous attempts, we could not isolate from the final reaction mixtures any such $\mathrm{ArIO}_{3}$ intermediates. In fact, after the addition of excess concd. hydrochloric acid to the cooled final reaction mixtures, we sometimes isolated the well-known [1-3,7] (dichloroiodo)arenes, $\mathrm{ArICl}_{2}$, in moderate yields, e.g. methyl 3-(dichloroiodo)benzoate, m.p. $108-109{ }^{\circ} \mathrm{C}$ (dec.), lit. [12] m.p. $104-105{ }^{\circ} \mathrm{C}$ (dec.), was isolated in $35 \%$ crude yield. These results suggest that the desirable aromatic iodine(VII) compounds must be obtained by a different route [9].

The aforesaid reaction mixtures were stirred at a temperature not exceeding $40{ }^{\circ} \mathrm{C}$ for 2 hours, then the temperature was slowly increased (over $30 \mathrm{~min}$ ) to $60-70{ }^{\circ} \mathrm{C}$, and the mixtures were finally stirred at this temperature for a further 40-50 min (at higher temperatures, the evolution of the iodine vapors and the appearance of some crystals were observed). During these reactions we did not observe any transient green or red colorations. After cooling, the final reaction mixtures were poured into ice-water containing a previously dissolved excess of $\mathrm{Na}_{2} \mathrm{SO}_{3}$ (a reducing agent) to obtain the expected iodoarenes, ArI, viz. 


$$
\left[\mathrm{ArIO}_{3}\right] \text { or other hypervalent species }+ \text { excess aq. } \mathrm{Na}_{2} \mathrm{SO}_{3} \underset{-\mathrm{NaHSO}_{4}}{\stackrel{\text { reduction }}{\longrightarrow}} \text { ArI }
$$

Activated arenes, e.g. anisole, acetanilide, and $N, N$-dimethylaniline, were easily oxidized under the given reaction conditions to form some tarry products, while nitrobenzene was unaffected, and was recovered as such after completing the reactions shown in Eqs. 1-5. Benzene was deliberately diiodinated to afford pure 1,4-diiodobenzene in 52\% yield. Benzonitrile, after completing all the reactions, gave only pure 3-iodobenzamide in 59\% yield; cf. our former paper [10]. Halobenzenes and the nine deactivated arenes shown in Table 1 gave the purified monoiodinated products in $27-88 \%$ yields. Their purities and homogeneities were checked by TLC and the corresponding melting/boiling points were all close to those reported in the literature. The proposed chemical structures were also supported by elemental analyses (\%), and comparison of the ${ }^{1} \mathrm{H}$ - and ${ }^{13} \mathrm{C}-\mathrm{NMR}$ solution spectra (not shown here) with the corresponding spectra of authentic specimens [11].

Table 1. Iodinated Pure Products Prepared and Volumes of Concd. $\mathrm{H}_{2} \mathrm{SO}_{4}$ Added.

\begin{tabular}{|c|c|c|c|c|c|}
\hline Substrate & Product & Yield $/ \%$ & $\begin{array}{l}\text { Concd } \mathrm{H}_{2} \mathrm{SO}_{4}{ }^{\text {a) }} \\
\mathrm{mL} / \mathrm{mmol}\end{array}$ & $\begin{array}{l}\text { Analysis/I\% } \\
\text { Calcd (Found) }\end{array}$ & $\begin{array}{l}\text { Mp or Bp } /{ }^{\circ} \mathrm{C} / \text { solvent }^{\text {b) }} \\
\left(\text { Lit }[12] \text { mp or bp } /{ }^{\circ} \mathrm{C}\right)\end{array}$ \\
\hline $\mathrm{C}_{6} \mathrm{H}_{6}$ & $1,4-\mathrm{I}_{2} \mathrm{C}_{6} \mathrm{H}_{4}$ & 52 & $2.13 / 40$ & 76.95 (76.7) & $125-127 / \mathbf{E}(129)$ \\
\hline $\mathrm{PhI}$ & $1,4-\mathrm{I}_{2} \mathrm{C}_{6} \mathrm{H}_{4}$ & 69 & $4.26 / 80$ & 76.95 (76.9) & 126-128/E (129) \\
\hline $\mathrm{PhBr}$ & $4-\mathrm{BrC}_{6} \mathrm{H}_{4} \mathrm{I}$ & 66 & $4.26 / 80$ & $44.86(44.8)$ & 89-91/E (91-92) \\
\hline $\mathrm{PhCl}$ & $4-\mathrm{ClC}_{6} \mathrm{H}_{4} \mathrm{I}$ & 27 & $5.33 / 100$ & $53.22(52.7)$ & 54-55/E (57) \\
\hline $\mathrm{PhCOOH}$ & $3-\mathrm{IC}_{6} \mathrm{H}_{4} \mathrm{COOH}$ & 82 & $6.39 / 120$ & $51.17(51.0)$ & 190-191/C (187-188) \\
\hline PhCOOMe & $3-\mathrm{IC}_{6} \mathrm{H}_{4} \mathrm{COOMe}$ & 82 & $6.39 / 120$ & $48.43(48.4)$ & 46-48/EW (54-55) \\
\hline PhCOOEt & $3-\mathrm{IC}_{6} \mathrm{H}_{4} \mathrm{COOEt}$ & 57 & $7.46 / 140$ & $45.97(45.9)$ & bp 180-181/69 (bp 150.5/15) \\
\hline $4-\mathrm{MeC}_{6} \mathrm{H}_{4} \mathrm{COOH}$ & 3-I-4- $\mathrm{MeC}_{6} \mathrm{H}_{3} \mathrm{COOH}$ & 88 & $6.39 / 120$ & $48.43(48.3)$ & 209-211/C (210-212) \\
\hline $4-\mathrm{ClC}_{6} \mathrm{H}_{4} \mathrm{COOH}$ & $3-\mathrm{I}-4-\mathrm{ClC}_{6} \mathrm{H}_{3} \mathrm{COOH}$ & 60 & $7.46 / 140$ & $44.93(44.5)$ & 214-216/EW (216-217) \\
\hline $4-\mathrm{MeC}_{6} \mathrm{H}_{4} \mathrm{NO}_{2}$ & 3-I-4- $\mathrm{MeC}_{6} \mathrm{H}_{4} \mathrm{NO}_{2}$ & 73 & $6.39 / 120$ & $48.25(47.8)$ & $52-53 / \mathbf{E}(61)$ \\
\hline $\mathrm{PhCONH}_{2}$ & $3-\mathrm{IC}_{6} \mathrm{H}_{4} \mathrm{CONH}_{2}$ & 61 & $12.78 / 240$ & $51.37(51.0)$ & 184-185/E (186.5) \\
\hline $\mathrm{PhCN}$ & $3-\mathrm{IC}_{6} \mathrm{H}_{4} \mathrm{CONH}_{2}$ & 59 & $13.85 / 260$ & $51.37(51.1)$ & 183-184/E (186.5) \\
\hline $\mathrm{PhCF}_{3}$ & $3-\mathrm{IC}_{6} \mathrm{H}_{4} \mathrm{CF}_{3}$ & 45 & $8.52 / 160$ & $46.65(46.2)$ & bp 70-72/40 (bp 182-183/760) \\
\hline
\end{tabular}

a) The amount of concd $\mathrm{H}_{2} \mathrm{SO}_{4}$ added dropwise to each of the cooled and stirred reaction mixtures.

b) Solvents used for recrystallization: $\mathbf{C}: \mathrm{CHCl}_{3}$; E: EtOH; EW: EtOH: $\mathrm{H}_{2} \mathrm{O}$ (1:1 v/v ).

\section{Conclusions}

We present in this short paper a quite novel approach to aromatic iodination, which allows one to effectively obtain iodoarenes from benzene, halobenzenes and some moderately deactivated arenes. The protonated transient meta-periodic acid, $\mathrm{O}_{4} \mathrm{I}^{+} \mathrm{H}_{2}$ (formed from the reagent grade $\mathrm{NaIO}_{4}$, which is sufficiently soluble in warm anhydrous and strongly acidic solutions, Eq. 1) was the sole iodinating agent present, capable of forming the stable C-I bond in the starting arenes. We failed however to isolate the expected aromatic iodine(VII) intermediates. 


\section{Experimental}

\section{General}

All the reagents and solvents were commercial materials (Aldrich) and were used without further purification. The melting/boiling points of pure iodinated products (Table 1) are uncorrected. Elemental microanalyses (\%I) were performed at the Institute of Organic Chemistry, the Polish Academy of Sciences in Warsaw. ${ }^{1} \mathrm{H}$ - and ${ }^{13} \mathrm{C}-\mathrm{NMR}$ spectra (not shown here) were recorded at the Medical University of Warsaw, at room temperature, with a Brucker Avance DMX $400 \mathrm{MHz}$ spectrometer in $\mathrm{CDCl}_{3}$ solutions, and with TMS added as an internal standard.

\section{Optimized Preparations of Iodoarenes from Arenes}

Powdered $\mathrm{NaIO}_{4}$ (3.51 g, $16.4 \mathrm{mmol} ; 2.5 \%$ excess) [for the iodination of halobenzenes: $3.42 \mathrm{~g}$ $\mathrm{NaIO}_{4}$ (16 mmol; 0\% excess), and for the preparation of 1,4-diiodobenzene from benzene: $3.60 \mathrm{~g}$ $\mathrm{NaIO}_{4}$ (16.8 mmol; 5\% excess)] was suspended with stirring in a mixture made up of glacial AcOH $(15 \mathrm{~mL})$ and $\mathrm{Ac}_{2} \mathrm{O}(10 \mathrm{~mL})$ cooled to $10{ }^{\circ} \mathrm{C}$. A chosen arene $(16 \mathrm{mmol}, 0 \%$ excess) [for the iodination of halobenzenes: $16.8 \mathrm{mmol}$; 5\% excess, and for the preparation of 1,4-diiodobenzene from benzene: 8 mmol; $0 \%$ excess] was added dropwise or portionwise. Still keeping the temperature at ca $10{ }^{\circ} \mathrm{C}$, a given volume (see Table 1) of concd. (95\%) $\mathrm{H}_{2} \mathrm{SO}_{4}$ was slowly added dropwise. The resulting reaction mixture was stirred at temperatures not exceeding $40{ }^{\circ} \mathrm{C}$ for 2 hours, then the temperature of the reaction mixture was slowly increased (within $30 \mathrm{~min}$ ) to $60-70{ }^{\circ} \mathrm{C}$, and the mixture was stirred at this temperature for a further 40-50 min. After cooling to r.t., the final reaction mixture was poured into stirred ice-water (150 g) containing previously dissolved $\mathrm{Na}_{2} \mathrm{SO}_{3}(4 \mathrm{~g})$. The oily crude products were extracted with $\mathrm{CHCl}_{3}\left(3 \times 20 \mathrm{~mL}\right.$ ), the combined extracts were dried over anhydrous $\mathrm{MgSO}_{4}$, filtered, the solvent was distilled off, and the oily residues were fractionated under reduced pressure. The solid crude products were collected by filtration, washed well with cold water, air-dried in the dark, and recrystallized from appropriate organic solvents to afford the purified iodinated products (Table 1). The yields given for pure products were calculated from the total amounts of those reagents (ArH or $\mathrm{NaIO}_{4}$ ) which were used in the reactions in strictly stoichiometric quantities ( $0 \%$ excess).

\section{References and Notes}

1. (a) Varvoglis, A. The Organic Chemistry of Polycoordinated Iodine; VCH: Weinheim, 1992; (b) Varvoglis, A. Hypervalent Iodine in Organic Synthesis; Academic Press: San Diego, 1997.

2. Zhdankin, V.V.; Stang, P.J. Polycoordinate Iodine Compounds. In Chemistry of Hypervalent Compounds; Akiba, K., Ed.; Wiley-VCH: New York, 1999; Chapter 11, p. 349.

3. Willgerodt, C. Die organischen Verbindungen mit mehrwertigem Jod; Enke Verlag: Stuttgart, 1914; p. 6.

4. Levitt, L.S.; Iglesias, R. The Periodination Reaction: Fast One-Step Synthesis of $\mathrm{C}_{6} \mathrm{I}_{6}$ from $\mathrm{C}_{6} \mathrm{H}_{6} . J$. Org. Chem. 1982, 47, 4470.

5. Mattern, D.L. Periodination of Benzene with Periodate/Iodide. J. Org. Chem. 1983, 48, 4772-4773. 
6. Inman, C.E.; Oesterling, R.E.; Tyczkowski, E.A. Reactions of Perchloryl Fluoride with Organic Compounds. I. Perchlorylation of Aromatic Compounds. J. Am. Chem. Soc. 1958, 80, 5286-5288.

7. Skulski, L. Organic Iodine(I, III, V) Chemistry: 10 Years of Development at the Medical University of Warsaw, Poland (1990-2000). Molecules 2000, 5, 1331-1371. Avail. at URL: http://www.mdpi.org/molecules/papers/51201311.pdf.

8. Skulski, L. Novel Easy Preparations of Some Aromatic Iodine(I, III, V) Reagents, Widely Applied in Modern Organic Synthesis. Molecules 2003, 8, 45-52. Avail. at URL: http://www.mdpi.org/molecules/papers/80100045.pdf.

9. In our opinion, the postulated transient $\left[\mathrm{IO}_{3}\right]^{+}$and $\left[\mathrm{ArIO}_{3}\right]$ species, probably present momentarily in the reaction mixtures, would quickly decompose in the anhydrous $\mathrm{AcOH} / \mathrm{Ac}_{2} \mathrm{O} / \mathrm{concd} . \mathrm{H}_{2} \mathrm{SO}_{4}$ medium to form more stable iodine(III) intermediates, $\mathrm{I}\left(\mathrm{OSO}_{3} \mathrm{H}\right)_{3}$ and $\mathrm{ArI}\left(\mathrm{OSO}_{3} \mathrm{H}\right)_{2}$, probably along with peracetic acid and/or peroxomonosulfuric acid. Such stable, though strongly hygroscopic, compounds as $\mathrm{I}_{2}\left(\mathrm{SO}_{4}\right)_{3}, \mathrm{I}\left(\mathrm{OSO}_{3} \mathrm{H}\right)_{3}, \mathrm{ArISO}_{4}$, and $\operatorname{ArI}\left(\mathrm{OSO}_{3} \mathrm{H}\right)_{2}$ are discussed and referred to the literature in the following review: Kasumov T. M.; Koz’min A. S.; Zefirov N. S. The Chemistry of Inorganic Sulfates and Sulfonates of Polyvalent Iodine (in Russian).Usp. Khim. 1997, 66, 936-952; Russ. Chem. Rev. 1997, 66, 843-857.

10. Lulinski, P.; Skulski, L. The Direct Iodination of Arenes with Chromium(VI) Oxide as the Oxidant. Bull. Chem. Soc. Jpn. 1997, 70, 1665-1669, see p. 1667, the right column.

11. Lulinski, P. Studies on Novel Methods of the Iodination of Aromatic Compounds (in Polish), Doctoral dissertation, Faculty of Pharmacy, Medical University of Warsaw, Poland, 2002.

12. Dictionary of Organic Compounds, 6th ed.; Chapman \& Hall: London, 1996.

Sample Availability: Contact the authors.

(C) 2005 by MDPI (http://www.mdpi.org). Reproduction is permitted for noncommercial purposes. 